\title{
CAMA
}

Centre for Applied Macroeconomic Analysis

\section{Capital Market Liberalization and Equity Market Interdependence}

\section{CAMA Working Paper 55/2020 May 2020}

\section{Renée Fry-McKibbin}

Crawford School of Public Policy, ANU

Centre for Applied Macroeconomic Analysis, ANU

\section{Ziyu Yan}

Crawford School of Public Policy, ANU

\section{Abstract}

This paper uses tests drawn from the literature on financial market contagion measured by changes in higher-order comoments to establish the patterns in the interdependence between equity markets in Shanghai and Shenzhen with Hong Kong as mainland China liberalized their capital market. On the announcement of the opening of the Shanghai market correlations rise, but subside by the launch. Following the launch changes in coskewness, cokurtosis and covolatility emerge. The liberalization process is complete by mid-September 2016 . 


\section{Keywords}

Shanghai-Hong Kong Stock Connect, Shenzhen Hong-Kong Stock Connect, Contagion, Spillovers

\section{JEL Classification}

G15

\section{Address for correspondence:}

(E) cama.admin@anu.edu.au

ISSN 2206-0332

The Centre for Applied Macroeconomic Analysis in the Crawford School of Public Policy has been established to build strong links between professional macroeconomists. It provides a forum for quality macroeconomic research and discussion of policy issues between academia, government and the private sector.

The Crawford School of Public Policy is the Australian National University's public policy school, serving and influencing Australia, Asia and the Pacific through advanced policy research, graduate and executive education, and policy impact. 


\title{
Capital Market Liberalization and Equity Market Interdependence*
}

\author{
Renée Fry-McKibbin, Ziyu Yan \\ CAMA, Crawford School of Public Policy, Australian National \\ University
}

May 21, 2020

\begin{abstract}
This paper uses tests drawn from the literature on financial market contagion measured by changes in higher-order comoments to establish the patterns in the interdependence between equity markets in Shanghai and Shenzhen with Hong Kong as mainland China liberalized their capital market. On the announcement of the opening of the Shanghai market correlations rise, but subside by the launch. Following the launch changes in coskewness, cokurtosis and covolatility emerge. The liberalization process is complete by mid-September 2016 .
\end{abstract}

KeYwords: Shanghai-Hong Kong Stock Connect; Shenzhen Hong-Kong Stock Connect; Contagion; Spillovers.

JEL Classifications: G15.

*The authors thank Kate McKinnon for research assistance. Author email addresses are renee.mckibbin@anu.edu.au and ziyu.yan@anu.edu.au. The corresponding author is Renée FryMcKibbin. 


\section{Introduction}

The launch of the Shanghai-Hong Kong Stock Connect Program allowing inbound and outbound portfolio investment between Shanghai and Hong Kong on November 17, 2014, provides a natural experiment to investigate the effects of capital market liberalization on the spillover of shocks across international financial markets. ${ }^{1}$ This paper applies tests from the contagion literature based on higher-order comoments (Fry et al., 2010; Fry-McKibbin and Hsiao, 2018; Fry-McKibbin et al., 2019) to test for changes in the transmission of shocks from the equity market of Hong Kong to those of Shanghai and Shenzhen. Shenzhen became the second Chinese equity market to open to Hong Kong in December 2016 with the Shenzhen-Hong Kong Stock Connect Program.

Models of contagion compare the transmission of shocks across asset markets in a noncrisis period with the transmission in a crisis period. A significant change is labeled contagion. If there is no significant change, the conclusion is that of asset market interdependence (Forbes and Rigobon, 2002). Similarly, capital market liberalization should lead to stable interdependence between asset markets over time. However, there is likely to be a period of adjustment as investors learn how markets interact in the liberalized environment. The new transmission of shocks across asset markets is akin to contagion. As the capital market moves from complete segmentation to liberalization, we expect a significant change in the spillovers between markets. Over time as the markets become interdependent, investors know how shocks in one market affect others, and changes in how shocks transmit should no longer be significant.

Market interdependence is often measured using the correlation coefficient. However, the non-normal distribution of asset returns means that the reliance on linear comoments at the expense of higher-order comoments can miss important channels linking markets. The presence of higher-order co-moments linking asset returns affects expectations of the return on risky assets, which in turn affects the portfolio selection of investors, and spillover effects between markets as investors balance their portfolios (Fry et al., 2010). Fry et al. (2010), Fry-McKibbin and Hsiao (2018) and Fry-McKibbin et al. (2019) derive tests examining changes in comoments between asset returns with a focus on measuring contagion. The tests examine changes in correlation, coskewness, cokurtosis, and covolatility. We redeploy these higher-order comoment tests to examine the significance of capital market liberalization on the interdependence of the equity markets of Shanghai and Shenzhen with Hong Kong. The tests show how liberalization affects market comoments and provides evidence on the duration taken for the establishment of stable equity market interdependence following the announcement and implementation of the liberalization policies. The application also provides evidence on how emerging markets opening their capital markets are affected by new relationships with equity markets in developed economies.

\footnotetext{
${ }^{1}$ Investors from mainland China and Hong Kong can freely trade stocks through security firms on the mainland and brokers in Hong Kong, or security trading service companies established by the Shanghai, Shenzhen, and Hong Kong Stock Exchanges. The opening of China through Hong Kong also provides a pathway for international investment in China.
} 
Two streams of literature examine the effects of capital market liberalization in China. The first compliments our approach focussing on equity market comovements with the majority using GARCH models to account for some higher-order comovement (Lin, 2017; Huo and Ahmed, 2017; Ma et al., 2019). For example, Lin (2017) and Huo and Ahmed (2017) find evidence of volatility spillovers and asymmetric spillovers using the BEKK-t-AGARCH model. The second stream approaches the question of the integration of the equity markets of mainland China with Hong Kong by examining the share price premium of dual-listed companies (Fan and Wang, 2017; Burdekin and Siklos, 2018). The work in this area tends to find that controlling for firm and market factors eliminates the $\mathrm{A}-\mathrm{H}$ share price premium in the post-connect period. Both streams imply higher financial market interdependence.

Our results show that stronger interdependence is evident in response to the first capital market liberalization announcement shown by a change in the correlation between Shanghai and Shenzhen with Hong Kong. However, by the time of the launch of the program, correlations are stable. After the launch, changes in coskewness, cokurtosis, and covolatility reflect the effects of liberalization through the linear and higher-order channels, which is complete by mid-September 2016. The Shenzhen equity market responds to the liberalization policies in tandem with Shanghai. Capital market liberalization through the announcement and launch of the Shenzhen-Hong Kong Program does not affect either the linear or nonlinear comoments.

The paper proceeds by examining the data in Section 2, setting out the testing framework in 3, and describing the empirical results in 4 . Concluding comments are in Section 5 .

\section{Data}

The data consists of weekly equity returns of the Hong Kong Hang Seng Index, the Shanghai Composite Index, and the Shenzhen Component Index over the sample January 4, 2012 - December, $272017 .{ }^{2}$ The choice of end of the sample period avoids the financial market turmoil in Hong Kong and China at the start of 2018. The data are percentage log-returns with 287 observations. Figure 1 plots the log of the weekly equity price indices and the percentage equity returns. Table 1 summarises the critical dates in the liberalization of the capital market for the opening of equity markets to inbound and outbound foreign investment with Hong Kong. The announcement of the Shanghai-Hong Kong Program on April 10, 2014, was followed by the launch on November 17, 2014. Just short of two years later came the announcement of the Shenzhen-Hong Kong Program, and the launch on December 5, 2016. The vertical lines in the figure highlight the announcement dates and the launch dates of the Programs.

The tests are conducted on differences in the comoments of the equity markets in the five regimes. These are change between the periods of the: i) pre-connect $(x)$ and Shanghai-Hong Kong announcement $\left(y_{1}\right)$; ii) Shanghai-Hong Kong announcement

\footnotetext{
${ }^{2}$ The data source is Yahoo Finance.
} 
Figure 1: Weekly equity prices (logs) and equity returns (percentage) for the Hong Kong Hang Seng Index, the Shanghai Composite Index and the Shenzhen Component Index, January 4, 2012 - December 27, 2017.
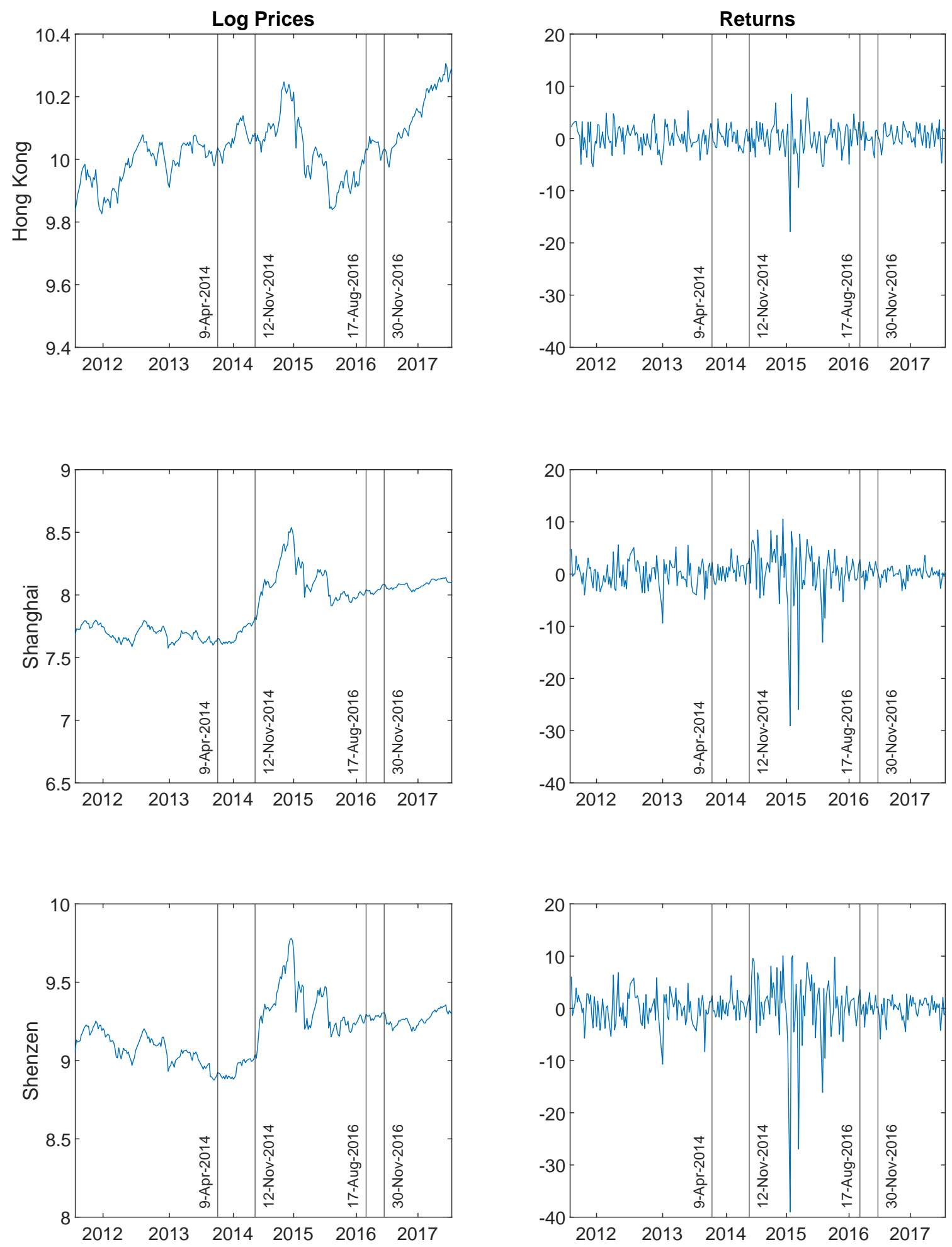

Notes: The vertical lines are: i) Shanghai-Hong Kong announcement; ii) Shanghai-Hong Kong launch; iii) Shenzhen-Hong Kong announcement; iv) Shenzhen-Hong Kong launch. 
Table 1: Timeline of the Shanghai-Hong Kong Stock Connect and the Shenzhen-Hong Kong Stock Connect Program announcements and launches, data identifier (Id.) and number of observations in each period. SH-HK refers to the Shanghai-Hong Kong Program, and SZ-HK refers to Shenzhen-Hong Kong Program.

Pre-connect

SH-HK announcement

SH-HK launch

SZ-HK announcement

SZ-HK launch

SZ-HK announcement and launch $x \quad$ January 4, 2012 - April 9, 2014

103

$y_{1} \quad$ April 10, 2014 - November 14, 2014

$y_{2} \quad$ November, 172014 - August 15, 2016

$y_{3}$ August 16, 2016 - December 4, 2016

$y_{4} \quad$ December 5, 2016 - December 27, 2017

$y_{5} \quad$ August 16, 2016 - December 27, 2017
86

15

52

67

$\left(y_{1}\right)$ and Shanghai-Hong Kong launch $\left(y_{2}\right)$; iii) Shenzhen-Hong Kong announcement $\left(y_{3}\right)$ and Shenzhen-Hong Kong launch $\left(y_{4}\right)$; and iv) the Shanghai-Hong Kong launch $\left(y_{2}\right)$ and Shenzhen-Hong Kong announcement and launch $\left(y_{5}\right)$ where the latter is the combination of $\left(y_{3}\right)$ and $\left(y_{4}\right)$. The announcement and launch periods are combined in $y_{5}$ because of the short duration of the Shenzhen-Hong Kong launch at only 15 observations.

To eliminate common factors as in the contagion literature, we estimate a $\operatorname{VAR}(1)$ between the three markets and use the residuals in the calculation of the test statistics. Controls include the Dow Jones equity returns, and a dummy for the financial crisis in Hong Kong and China from July 8, 2015, to January 27, 2016.

Tables 2 and 3 present the descriptive and comoment statistics of the data in each period. The comoment statistics of the correlation, coskewness, cokurtosis, and covolatility are calculated with respect to Hong Kong. The tables show that the moments and comoments change over time, sometimes switch signs, and point to the non-normality of the data with the characteristics of peakedness and fat tails.

\section{Testing Framework}

Fry et al. (2010), Fry-McKibbin and Hsiao (2018) and Fry-McKibbin et al. (2019) demonstrate that it is reasonable to test for changes in the relationships between asset markets through the higher-order comoments of correlation, coskewness, cokurtosis, and covolatility, respectively. They derive Lagrange Multiplier test statistics under 
Table 2: Descriptive statistics of the weekly equity returns of Hong Kong (HSI), Shanghai (SSE) and Shenzhen (SZE) in the pre-connect, announcement and launch periods.

\begin{tabular}{|c|c|c|c|c|}
\hline Market & Mean & Variance & Skewness & Kurtosis \\
\hline & \multicolumn{4}{|c|}{ Pre-connect: (January 4, 2012 - April 9, 2014) } \\
\hline HSI & -0.079 & 2.006 & -0.019 & 6.079 \\
\hline SSE & -0.406 & 2.606 & -0.365 & 8.482 \\
\hline \multirow[t]{2}{*}{$\mathrm{SZE}$} & -0.427 & 3.160 & -0.442 & 11.116 \\
\hline & \multicolumn{4}{|c|}{ SH-HK announcement: (April 10, 2014 - November 16, 2014) } \\
\hline HSI & -0.132 & 1.888 & 0.530 & 4.835 \\
\hline SSE & 0.238 & 1.848 & 0.606 & 6.433 \\
\hline \multirow[t]{2}{*}{ SZE } & 0.091 & 2.173 & 1.168 & 10.746 \\
\hline & \multicolumn{4}{|c|}{ SH-HK launch: (November, 172014 - August 15, 2016) } \\
\hline HSI & 0.110 & 2.567 & -1.606 & 33.121 \\
\hline SSE & 0.618 & 5.411 & -1.918 & 56.000 \\
\hline \multirow[t]{2}{*}{ SZE } & 0.674 & 6.587 & -2.199 & 81.310 \\
\hline & \multicolumn{4}{|c|}{ SZ-HK announcement (August 16, 2016 - December 4, 2016) } \\
\hline HSI & -0.159 & 2.046 & -1.907 & 15.824 \\
\hline SSE & 0.166 & 1.261 & 0.644 & 3.514 \\
\hline \multirow[t]{2}{*}{ SZE } & 0.048 & 1.673 & 1.007 & 5.765 \\
\hline & \multicolumn{4}{|c|}{ SZ-HK launch (December 5, 2016 - December 27, 2017) } \\
\hline HSI & 0.097 & 1.847 & -0.411 & 6.468 \\
\hline SSE & -0.402 & 1.377 & -0.059 & 5.791 \\
\hline SZE & -0.335 & 1.974 & -0.946 & 8.381 \\
\hline
\end{tabular}


Table 3: Comoment statistics of the weekly equity returns of Shanghai (SSE) and Shenzhen (SZE) with Hong Kong (HSI) in the pre-connect, announcement and launch periods.

\begin{tabular}{|c|c|c|c|c|c|c|}
\hline $\begin{array}{l}\text { Market } \\
(j)\end{array}$ & $\begin{array}{c}\text { Correlation } \\
\left(r_{H S I, t} r_{j, t}\right)\end{array}$ & $\begin{array}{c}\text { Coskewness } \\
\left(r_{H S I, t}^{2} r_{j, t}\right)\end{array}$ & $\begin{array}{c}\text { Coskewness } \\
\left(r_{H S I, t} r_{j, t}^{2}\right)\end{array}$ & $\begin{array}{c}\text { Cokurtosis } \\
\left(r_{H S I, t}^{3} r_{j, t}\right)\end{array}$ & $\begin{array}{c}\text { Cokurtosis } \\
\left(r_{H S I, t} r_{j, t}^{3}\right)\end{array}$ & $\begin{array}{c}\text { Covolatility } \\
\left(r_{H S I, t}^{2} r_{j, t}^{2}\right)\end{array}$ \\
\hline \multicolumn{7}{|c|}{ Pre-connect: (January 4, 2012 - April 9, 2014) } \\
\hline SSE & 0.505 & -0.131 & -0.011 & 1.785 & 1.734 & 1.726 \\
\hline SZE & 0.494 & -0.191 & -0.004 & 1.776 & 1.632 & 1.691 \\
\hline \multicolumn{7}{|c|}{ SH-HK announcement: (April 10, 2014 - November 16, 2014) } \\
\hline SSE & 0.540 & 0.629 & 0.712 & 2.299 & 1.658 & 1.993 \\
\hline SZE & 0.638 & 0.915 & 0.723 & 3.414 & 2.009 & 2.569 \\
\hline \multicolumn{7}{|c|}{ SH-HK launch: (November, 172014 - August 15, 2016) } \\
\hline SSE & 0.526 & -1.666 & -1.662 & 8.806 & 10.524 & 9.456 \\
\hline SZE & 0.514 & -1.957 & -1.846 & 11.212 & 11.544 & 11.388 \\
\hline \multicolumn{7}{|c|}{ SZ-HK announcement (August 16, 2016 - December 4, 2016) } \\
\hline SSE & 0.410 & 0.012 & -0.728 & 1.005 & 2.802 & 1.251 \\
\hline $\mathrm{SZE}$ & 0.553 & -0.079 & -0.844 & 1.515 & 3.531 & 1.827 \\
\hline \multicolumn{7}{|c|}{ SZ-HK launch (December 5, 2016 - December 27, 2017) } \\
\hline SSE & 0.490 & 0.137 & -0.063 & 2.039 & 1.644 & 1.718 \\
\hline SZE & 0.288 & -0.190 & -0.178 & 1.501 & 1.032 & 1.319 \\
\hline
\end{tabular}


the assumption that the joint probability density function of asset returns is from the non-normal bivariate generalized exponential distribution. Tables 2 and 3 support the use of the tests in the empirical application as the data properties change at the higher-order level. This section summarises the comoment liberalization tests.

\subsection{Correlation Liberalization Test}

The correlation change test set out in Fry et al. (2010) tests for a significant change in the correlation between asset markets $i$ and $j$ over two periods, $x$ and $y$, respectively. The correlation liberalization test statistic $(C R)$ is

$$
\begin{gathered}
C R=\left(\frac{\hat{\vartheta}_{y \mid x_{i}}-\hat{\rho}_{x}}{\sqrt{\left(\operatorname{var}\left(\hat{\vartheta}_{y \mid x_{i}}-\hat{\rho}_{x}\right)\right.}}\right)^{2}, \\
\hat{\vartheta}_{y \mid x_{i}}=\frac{\hat{\rho}_{y}}{\sqrt{1+\delta\left(1-\hat{\rho}_{y}^{2}\right)}}, \\
\delta=\frac{\left(s_{y, i}^{2}-s_{x, i}^{2}\right)}{s_{x, i}^{2}} .
\end{gathered}
$$

The unconditional correlation coefficients of markets $i$ and $j$ in periods $x$ and $y$ are $\hat{\rho}_{x}$ and $\hat{\rho}_{y}$. The conditional correlation coefficient in period $y$ is $\hat{\vartheta}_{y \mid x_{i}}$ where $\delta$ is the change in the ratio of the market volatilities in period $j$ relative the larger market $(i)$ in period $x$, and $s_{x, i}^{2}$ and $s_{y, i}^{2}$ are the respective variances of the returns. The expression for the variance of the test statistic $\left(\operatorname{var}\left(\hat{\vartheta}_{y \mid x_{i}}-\hat{\rho}_{x}\right)\right.$ is contained in Fry et al. (2010). The test extends Forbes and Rigobon (2002) by generalizing the expression for the variance of the test statistic to allow for some dependence between assets and squares the test to make it a two-sided test. Under the null hypothesis, $C R$ is asymptotically distributed as $C R \stackrel{d}{\rightarrow} \chi_{1}^{2}$.

\subsection{Coskewness Liberalization Tests}

The coskewness tests capture changes in the asymmetric dependence between asset markets $i$ and $j$ over periods $x$ and $y$ as derived in Fry et al. (2010). The asymmetry comes through dependence between the expected returns in one market with the volatility of returns in a second market. There are two forms of coskewness liberalization tests denoted $C S_{12}$ and $C S_{21}$.

The first form measures the dependence between expected returns in market $i$ and squared returns in market $j$. The coskewness coefficients in periods $x$ and $y$ are 


$$
\hat{\varphi}_{x}\left(r_{i}, r_{j}^{2}\right)=\frac{1}{T_{x}} \sum_{t=1}^{T_{x}}\left(\frac{r_{i, t}-\hat{\mu}_{i, x}}{\hat{\sigma}_{i, x}}\right)\left(\frac{r_{j, t}-\hat{\mu}_{j, x}}{\hat{\sigma}_{j, x}}\right)^{2}
$$

and

$$
\hat{\varphi}_{y}\left(r_{i}, r_{j}^{2}\right)=\frac{1}{T_{y}} \sum_{t=1}^{T_{y}}\left(\frac{r_{i, t}-\hat{\mu}_{i, y}}{\hat{\sigma}_{i, y}}\right)\left(\frac{r_{j, t}-\hat{\mu}_{j, y}}{\hat{\sigma}_{j, y}}\right)^{2},
$$

respectively.

The asset returns in each period are demeaned and standardized using the respective sample means $\left(\hat{\mu}_{i, x}, \hat{\mu}_{j, x}, \hat{\mu}_{i, y}, \hat{\mu}_{j, y}\right)$, and standard deviations $\left(\hat{\sigma}_{i, x}, \hat{\sigma}_{j, x}, \hat{\sigma}_{i, y}, \hat{\sigma}_{j, y}\right) . T_{x}$ and $T_{y}$ are the sample sizes for each period.

The coskewness liberalization test statistic comparing the first form of coskewness of markets in periods $x$ and $y$ is

$$
C S_{12}=\left[\frac{\hat{\varphi}_{y}\left(r_{i}, r_{j}^{2}\right)-\hat{\varphi}_{x}\left(r_{i}, r_{j}^{2}\right)}{\sqrt{\frac{4 \hat{\vartheta}_{y \mid x_{i}}+2}{T_{y}}+\frac{4 \hat{\rho}_{x}^{2}+2}{T_{x}}}}\right]^{2} .
$$

The second form of coskewness reverses the asymmetric dependence to be through the volatility in asset asset $i$ and the expected returns in asset $j$. The coskewness statistics are denoted $\hat{\varphi}_{x}\left(r_{i}^{2}, r_{j}\right)$ and $\hat{\varphi}_{y}\left(r_{i}^{2}, r_{j}\right)$.

The second coskewness liberalization test is

$$
C S_{12}=\left[\frac{\hat{\varphi}_{y}\left(r_{i 2}, r_{j}\right)-\hat{\varphi}_{x}\left(r_{i}^{2}, r_{j}\right)}{\sqrt{\frac{4 \hat{\vartheta}_{y \mid x_{i}}+2}{T_{y}}+\frac{4 \hat{\rho}_{x}^{2}+2}{T_{x}}}}\right]^{2} .
$$

Under the null hypotheses, $C S_{12}$ and $C S_{21}$ are asymptotically distributed as $C S_{12}, C S_{21} \stackrel{d}{\rightarrow}$ $\chi_{1}^{2}$.

\subsection{Cokurtosis Liberalization Tests}

The cokurtosis spillover tests capture changes in dependence measured in the fourthorder comoments of the joint distribution of asset markets $i$ and $j$ (Fry-McKibbin and Hsiao, 2018). Three forms of cokurtosis capture the dependence between expected returns in one market and skewness in a second market and vice-versa, and between volatility dependence across the markets. For convenience, we refer to the final form 
of cokurtosis as covolatility. The cokurtosis and covolatility liberalization tests are denoted $C K_{13}, C K_{31}$ and $C V$.

The first form of cokurtosis measures the dependence between expected returns in market $i$ and the skewness of returns in market $j$. The cokurtosis coefficients for this case in periods $x$ and $y$ are

$$
\hat{\xi}_{x}\left(r_{i}, r_{j}^{3}\right)=\frac{1}{T_{x}} \sum_{t=1}^{T_{x}}\left(\frac{r_{i, t}-\hat{\mu}_{i, x}}{\hat{\sigma}_{i, x}}\right)\left(\frac{r_{j, t}-\hat{\mu}_{j, x}}{\hat{\sigma}_{j, x}}\right)^{3}-3 \hat{\rho}_{x}
$$

and

$$
\hat{\xi}_{y}\left(r_{i}, r_{j}^{3}\right)=\frac{1}{T_{y}} \sum_{t=1}^{T_{y}}\left(\frac{r_{i, t}-\hat{\mu}_{j, y}}{\hat{\sigma}_{j, y}}\right)\left(\frac{r_{j, t}-\hat{\mu}_{j, y}}{\hat{\sigma}_{j, y}}\right)^{3}-3 \hat{\vartheta}_{y \mid x_{i}} .
$$

The cokurtosis liberalization test statistic comparing the first form of cokurtosis of markets in period $x$ and $y$ is

$$
C K_{13}=\left[\frac{\hat{\xi}_{y}\left(r_{i}, r_{j}^{3}\right)-\hat{\xi}_{x}\left(r_{i}, r_{j}^{3}\right)}{\sqrt{\frac{18 \hat{\vartheta}_{y \mid x_{i}}^{2}+6}{T_{y}}+\frac{18 \hat{\rho}_{x}^{2}+6}{T_{x}}}}\right]^{2}
$$

The second form of cokurtosis reverses the dependence to be through the skewness in asset $i$ and the expected returns in asset $j$ with the statistics denoted $\hat{\xi}_{x}\left(r_{i}^{3}, r_{j}\right)$ and $\hat{\xi}_{y}\left(r_{i}^{3}, r_{j}\right)$.

The cokurtosis liberalization test statistic comparing the second form of cokurtosis of markets in periods $x$ and $y$ is

$$
C K_{31}=\left[\frac{\hat{\xi}_{y}\left(r_{i}^{3}, r_{j}\right)-\hat{\xi}_{x}\left(r_{i}^{3}, r_{j}\right)}{\sqrt{\frac{18 \hat{\vartheta}_{y \mid x_{i}}^{2}+6}{T_{y}}+\frac{18 \hat{\rho}_{x}^{2}+6}{T_{x}}}}\right]^{2} .
$$

Covolatility measures dependence through the volatility in asset $i$ and the volatility in asset $j$. The expressions for the covolatility statistics in periods $x$ and $y$ are

$$
\hat{\Phi}_{x}\left(r_{i}^{2}, r_{j}^{2}\right)=\frac{1}{T_{x}} \sum_{t=1}^{T_{x}}\left(\frac{r_{i, t}-\hat{\mu}_{i, x}}{\hat{\sigma}_{i, x}}\right)^{2}\left(\frac{r_{j, t}-\hat{\mu}_{j, x}}{\hat{\sigma}_{j, x}}\right)^{2}-\left(1+2 \hat{\rho}_{x}^{2}\right),
$$

and

$$
\hat{\Phi}_{y}\left(r_{i}^{2}, r_{j}^{2}\right)=\frac{1}{T_{y}} \sum_{t=1}^{T_{y}}\left(\frac{y_{i, t}-\hat{\mu}_{y, t}}{\hat{\sigma}_{y, t}}\right)^{2}\left(\frac{y_{j, t}-\hat{\mu}_{y, j}}{\hat{\sigma}_{y, j}}\right)^{2}-\left(1+2 \hat{\vartheta}_{y \mid x_{i}}^{2}\right) .
$$

The covolatility liberalization test statistic comparing covolatility of markets in periods $x$ and $y$ is 


$$
C V=\left[\frac{\hat{\Phi}_{y}\left(r_{i}^{2}, r_{j}^{2}\right)-\hat{\Phi}_{x}\left(r_{i}^{2}, r_{j}^{2}\right)}{\sqrt{\frac{4 \hat{\vartheta}_{y \mid x_{i}}^{4}+16 \hat{\vartheta}_{y \mid x_{i}}^{2}+4}{T_{y}}+\frac{4 \hat{\rho}_{x}^{4}+16 \hat{\rho}_{x}^{2}+4}{T_{x}}}}\right]^{2} .
$$

Under the null hypothesis, $C K_{13}, C K_{31}$ and $C V$ are asymptotically distributed as $C K_{13}, C K_{31}, C V \stackrel{d}{\rightarrow} \chi_{1}^{2}$.

\section{Results}

This section presents the comoment liberalization test statistics for each of the periods of liberalization compared to the preceding period. It then presents rolling statistics to show the evolution of market interdependence between Shanghai, Shenzhen, and Hong Kong as the capital market liberalized.

\subsection{Static Analysis}

Table 4 presents the comoment liberalization test statistics of the asset returns of Shanghai and Shenzhen with Hong Kong in the four periods specified in Table 1. The $p$-values are in parentheses. The first panel of the table compares the comoments before and after the announcement of the Shanghai-Hong Kong Program. The table shows no announcement effects associated with the program as there is almost no change in the interdependence between Hong Kong and Shanghai. The only statistic that is significant at the $5 \%$ level is the $C S_{12}$ test measuring the relationship between the level of the market in Hong Kong with the volatility in Shanghai and Shenzhen.

With the launch of the Shanghai-Hong Kong Program, all of the comoments for Shanghai and Shenzhen significantly change except for the correlation of the Shanghai and Hong Kong equity returns providing evidence that capital market liberalization changed the relationship between the markets. Ma et al. (2019) also finds that the correlation between Shanghai and Hong Kong does not significantly increase after the launch of the program. The higher-order relationships are the dominant channels of change. The launch of the program intensifies the asymmetric spillovers across markets, as shown through the significance of the coskewness liberalization tests $\left(C S_{12}, C S_{21}\right)$, and the cokurtosis liberalization tests $\left(C K_{13}, C K_{31}\right)$. Volatility spillovers $(C V)$ also significantly change. In this case, looking for changes in interdependence through correlations and not other comoments miss all of the significant channels of change.

The comoment liberalization change statistics show no reaction of equity markets to the Shenzhen-Hong Kong launch. The second last panel in Table 4 compares the announcement and launch periods, while the last panel in the table compares the Shenzhen-Hong Kong announcement and launch combined with the data from the launch of the Shanghai-Hong Kong Program. None of the statistics are significant in 
these periods indicating that Shenzhen was already integrated with Hong Kong via the Shanghai linkage from the time of the launch of the first program. The Shanghai and Shenzhen equity markets respond in the same way in all but one of the tests conducted across the compared periods, confirming the early integration of Shenzhen with Shanghai and Hong Kong. Equity market interdependence was complete by the end of the sample, with no new transmission linkages evident.

\subsection{Dynamic Analysis}

Figure 2 shows the dynamic evolution of the liberalization of the Shanghai and Shenzhen equity markets with Hong Kong. The comoment liberalization statistics are calculated on a sample $x$ and $y$, which both roll through time. The non-overlapping samples are of size $T_{x}=T_{y}=30$. The horizontal line corresponds to the critical value at the 5 percent level of significance.

The results provide insights into the evolution of the financial liberalization process. For both Shanghai and Shenzhen, there is very little evidence of change in interdependence with Hong Kong before the Shanghai-Hong Kong Program announcement as expected given lack of direct linkages. ${ }^{3}$ On the announcement of the Shanghai-Hong Kong Program, there is evidence that the correlations between Hong Kong and Shanghai and Shenzhen increase. However, significant changes in the correlations cease coinciding with the program launch.

All of the change in market interdependence occurs in the higher-order comoments following the launch. The peak of the effects of liberalization on the comoments occurs between July 8 and August 12, 2015. Higher-order changes are not significant during the Shanghai-Hong Kong Program announcement period. The liberalization process is mostly complete by September 2016. After this time, there is little evidence of changes in the interdependence between Hong Kong and Shanghai and Hong Kong and Shenzhen through any comoment.

\section{Conclusions}

This paper uses tests from the financial market contagion literature of changes in higher-order comoments to establish patterns in the interdependence between equity markets as a country liberalizes their capital market. Liberalization should lead to stable interdependence between asset markets. However, there may be an adjustment period where the spillovers of shocks change, like when modeling contagion. The Shanghai-Hong Kong Stock Connect and subsequent Shenzhen-Hong Kong Stock Con-

\footnotetext{
${ }^{3}$ Some linkages between the equity markets of mainland China and Hong Kong did exist before the Connect programs. After the return of Hong Kong to China in 1997, many mainland Chinese companies went public on the Hong Kong stock market by listing on both the Shanghai and Hong Kong stock exchanges. However, before the Connect Programs, there was no ability for direct cross-border investments.
} 
Table 4: Liberalization statistics of the change in the comoments of the weekly equity returns of Shanghai (SSE) and Shenzhen (SZE) with Hong Kong (HSI) in the preconnect, announcement and launch periods. The dates of the periods are contained in Table 1. The $p$-values are in parentheses. A* denotes significance at the $5 \%$ level.

\begin{tabular}{|c|c|c|c|c|c|c|}
\hline Market & $\mathrm{CR}$ & $\mathrm{CS}_{12}$ & $\mathrm{CS}_{21}$ & $\mathrm{CK}_{13}$ & $\mathrm{CK}_{31}$ & $\mathrm{CV}$ \\
\hline \multicolumn{7}{|c|}{ Pre-connect $(x)$ and SH-HK announcement $\left(y_{1}\right)$} \\
\hline \multirow[t]{2}{*}{ SSE } & 0.171 & $4.185^{*}$ & 3.782 & 0.237 & 0.125 & 0.052 \\
\hline & $(0.679)$ & $(0.041)$ & $(0.052)$ & $(0.626)$ & $(0.724)$ & $(0.819)$ \\
\hline \multirow[t]{2}{*}{ SZE } & 2.017 & $7.943^{*}$ & 3.441 & 2.292 & 0.028 & 0.514 \\
\hline & $(0.156)$ & $(0.005)$ & $(0.064)$ & $(0.130)$ & $(0.867)$ & $(0.473)$ \\
\hline \multicolumn{7}{|c|}{ SH-HK announcement $\left(y_{1}\right)$ and SH-HK launch $\left(y_{2}\right)$} \\
\hline \multirow[t]{2}{*}{$\mathrm{SSE}$} & 0.847 & $38.556^{*}$ & $41.234^{*}$ & $98.662^{*}$ & $177.861^{*}$ & $156.291^{*}$ \\
\hline & $(0.357)$ & $(0.000)$ & $(0.000)$ & $(0.000)$ & $(0.000)$ & $(0.000)$ \\
\hline \multirow{2}{*}{ SZE } & $4.045^{*}$ & $54.313^{*}$ & $43.465^{*}$ & $131.912^{*}$ & $191.295^{*}$ & $192.223^{*}$ \\
\hline & $(0.044)$ & $(0.000)$ & $(0.000)$ & $(0.000)$ & $(0.000)$ & $(0.000)$ \\
\hline \multicolumn{7}{|c|}{ SZ-HK announcement $\left(y_{3}\right)$ and SZ-HK launch $\left(y_{4}\right)$} \\
\hline \multirow[t]{2}{*}{ SSE } & 0.267 & 0.066 & 1.855 & 0.567 & 2.810 & 0.097 \\
\hline & $(0.606)$ & $(0.798)$ & $(0.173)$ & $(0.452)$ & $(0.094)$ & $(0.756)$ \\
\hline \multirow[t]{2}{*}{$\mathrm{SZE}$} & 1.239 & 0.047 & 1.700 & 0.532 & 3.478 & 0.012 \\
\hline & $(0.266)$ & $(0.828)$ & $(0.192)$ & $(0.466)$ & $(0.062)$ & $(0.911)$ \\
\hline \multicolumn{7}{|c|}{ SH-HK launch $\left(y_{2}\right)$ and SZ-HK announcement/launch $\left(y_{5}\right)$} \\
\hline \multirow[t]{2}{*}{ SSE } & 0.097 & 0.033 & 1.249 & 0.332 & 2.005 & 0.016 \\
\hline & $(0.756)$ & $(0.855)$ & $(0.264)$ & $(0.564)$ & $(0.157)$ & $(0.900)$ \\
\hline \multirow[t]{2}{*}{ SZE } & 0.953 & 0.017 & 1.047 & 0.304 & 2.052 & 0.025 \\
\hline & $(0.329)$ & $(0.897)$ & $(0.306)$ & $(0.581)$ & $(0.152)$ & $(0.875)$ \\
\hline
\end{tabular}


Figure 2: Rolling liberalization statistics of the change in the comoments for the equity returns of the Hong Kong Hang Seng Index with the Shanghai Composite Index and the Shenzhen Component Index, January 4, 2012 - December 27, 2017.
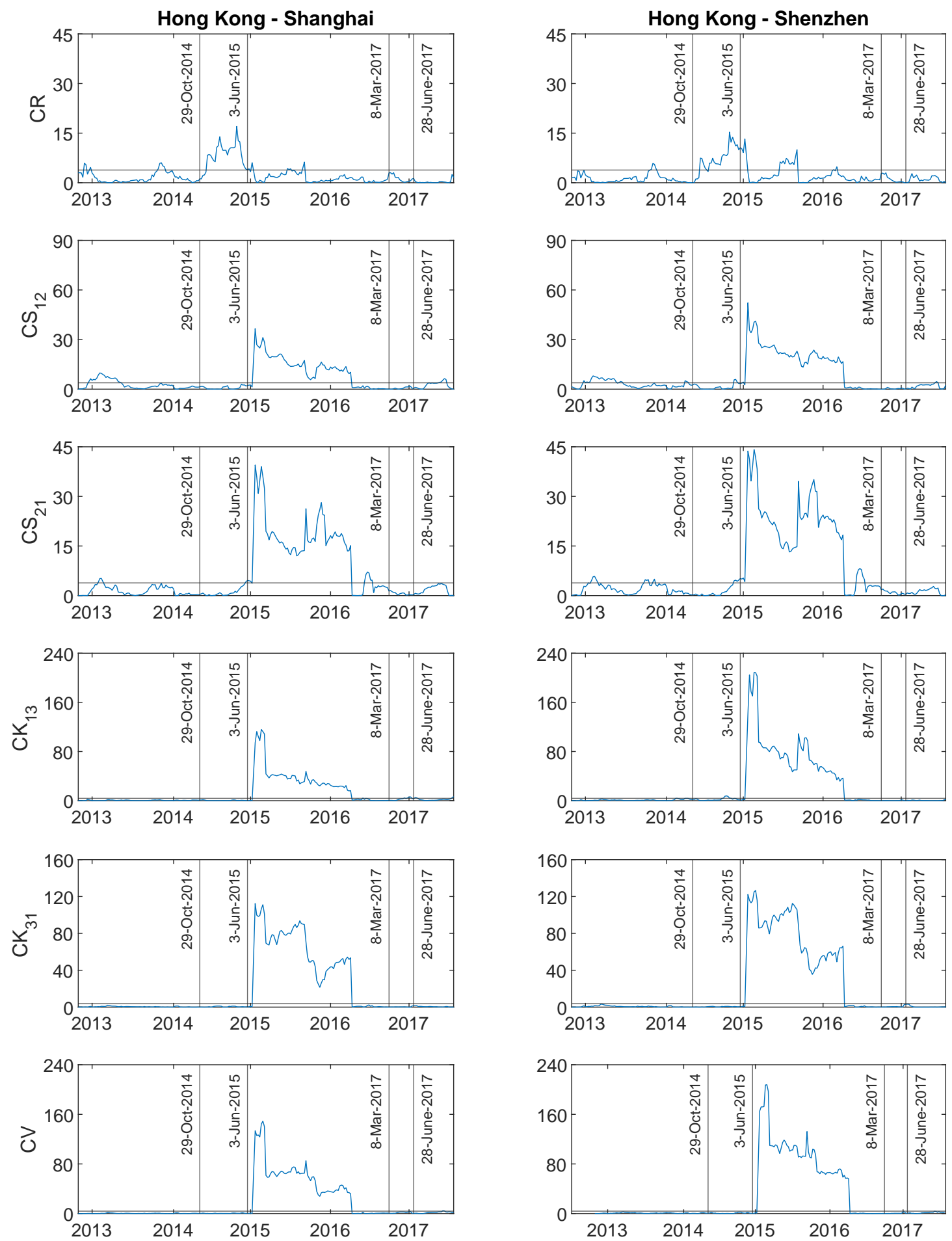

Notes: The rolling windows are $T_{x}=T_{y}=30$ observations. The vertical lines are: i) Shanghai-Hong Kong announcement; ii) Shanghai-Hong Kong launch; iii) Shenzhen-Hong Kong announcement; iv) Shenzhen-Hong Kong launch 
nect Programs opening China to portfolio investment between Shanghai and Hong Kong in 2014, provides the pertinent application.

Our results show an increase in interdependence in response to the Shanghai-Hong Kong Connect liberalization policy announcement through changing correlations between Shanghai and Shenzhen with Hong Kong. However, by the time of the program launch, the change subsides. However, after the launch, significant changes in coskewness, cokurtosis, and covolatility reflect the effects of liberalization. Changes in interdependence coinciding with the liberalization process are complete by mid-September 2016. The Shenzhen equity market moves in tandem with that of Shanghai.

\section{References}

Burdekin, R.C., Siklos, P.L., 2018. Quantifying the impact of the November 2014 Shanghai-Hong Kong Stock Connect. International Review of Economics \& Finance 57, 156-163.

Fan, Q., Wang, T., 2017. The impact of Shanghai-Hong Kong Stock Connect policy on AH share price premium. Finance Research Letters 21, 222-227.

Forbes, K.J., Rigobon, R., 2002. No contagion, only interdependence: Measuring stock market comovements. The Journal of Finance 57, 2223-2261.

Fry, R., Martin, V.L., Tang, C., 2010. A new class of tests of contagion with applications. Journal of Business \& Economic Statistics 28, 423-437.

Fry-McKibbin, R., Hsiao, C.Y.L., 2018. Extremal dependence tests for contagion. Econometric Reviews 37, 626-649.

Fry-McKibbin, R., Hsiao, C.Y.L., Martin, V.L., 2019. Joint tests of contagion with applications. Quantitative Finance 19, 473-490.

Huo, R., Ahmed, A.D., 2017. Return and volatility spillovers effects: Evaluating the impact of Shanghai-Hong Kong Stock Connect. Economic Modelling 61, 260-272.

Lin, W., 2017. Modeling volatility linkages between Shanghai and Hong Kong stock markets before and after the connect program. Economic Modelling 67, 346-354.

Ma, R., Deng, C., Cai, H., Zhai, P., 2019. Does Shanghai-Hong Kong Stock Connect drive market comovement between Shanghai and Hong Kong: A new evidence. The North American Journal of Economics and Finance 50, 100980. 